\title{
The Four Dimensions of Embodiment and the Experience of Illness
}

\author{
Māra Grīnfelde \\ Institute of Philosophy and Sociology, University of Latvia \\ Department of Humanities, Riga Stradins University \\ mara.grinfelde@gmail.com
}

Received 28 February 2018; accepted 28 April 2018; published 30 September 2018.

\begin{abstract}
In this paper I will try to systematically lay out and describe the multiple dimensions of the embodied experience of illness, which until recently has been the main focus within the field of the phenomenology of medicine. In order to do this, I will turn to analysis of the nature of embodiment in Husserl's phenomenology. I will argue that based on Husserl's phenomenology of the body, one can distinguish four ways of experiencing one's body, or four dimensions of embodiment. I will distinguish between experience of one's body as 1) a bearer of sensations (the affective dimension of embodiment); 2) a seat of free movement, characterized by the faculty of "I can" (the functional dimension of embodiment); 3) a material thing in a causal relationship with the material world (the material dimension of embodiment); 4) a material thing embedded in a social context (the social dimension of embodiment). I will then apply the proposed classification of dimensions of embodiment to the experience of illness, focusing on the various ways these dimensions have been used within the phenomenology of medicine. This serves two purposes. Firstly, it provides a framework for classification of the existing interpretations of the experience of illness; secondly, it opens up a way for a comprehensive analysis of the experience of illness which includes both individual and social aspects of embodiment as well as their mutual intertwining.
\end{abstract}

Keywords: embodiment; Husserl; illness; lived body; phenomenology of medicine.

\section{Introduction}

During its development in the $20^{\text {th }}$ and $21^{\text {st }}$ centuries, phenomenology has been engaged in dialogue with other disciplines, including medicine. Since the end of the $20^{\text {th }}$ century, many philosophers (Zaner, 1981; Leder, 1990, 2016; Toombs, 1987, 1992; Carel, 2008, 2016; 
Aho \& Aho, 2009; Zeiler \& Käll, 2014; Svenaeus, 2011, 2018; Slatman, 2014a, 2014b) have written about the importance of the phenomenological approach to medical practice, focusing on embodied experiences of illness, pain, suffering, disability, dying and organ transplantation. The phenomenological approach, according to them, gives access to the immediate embodied experience of the subject prior to any causal explanations of this experience, capturing meaning structures of the everyday world as they appear to the experiencing subject. Phenomenologists of medicine thus do not focus on the biological dysfunctions of the body and their causes which fall under the domain of empirical sciences, but on the meaning one attributes to the experience of these dysfunctions. At the center of their research are descriptions of the embodied experience of illness; namely, descriptions of the way illness is lived by the person who is sick. ${ }^{1}$ Consequently, these authors have made a distinction between purely scientific anatomical/pathological models of disease and the understanding of illness-as-lived (Toombs, 1987, p. 221; Svenaeus, 2011, pp. 337-338; Carel, 2016, pp. 15-17). While the former presupposes an external perspective of the patient's body as a material and mechanized object (Marcum, 2004, p. 311), the latter constitutes an internal perspective on embodiment which is of enormous practical significance for patient treatment and care (Slatman, 2014b, p. 549; Toombs, 2001, p. 248).

In developing interpretations of patients' embodied experience of illness, phenomenologists of medicine have engaged in discussions with the phenomenological tradition, especially focusing on ideas concerning the body. There are a number of phenomenologists whose ideas are used in the contemporary phenomenology of medicine, most notably Edmund Husserl, Maurice Merleau-Ponty, Jean-Paul Sartre, Martin Heidegger and HansGeorg Gadamer. ${ }^{2}$ Depending on the theoretical framework used in describing the experience of illness, phenomenologists of medicine have focused on different dimensions of embodiment. It has been argued that most of them have been focusing on the body's subject-side, emphasizing the view of the body as "a condition of possibility for worlddisclosing" (Slatman, 2014b, p. 549).

While I agree with the observation that the focus on the body's subject-side has been at the center of phenomenological interpretations of the experience of illness developed so far, two things should be mentioned. Firstly, the body's subject-side expresses not only the view of the body as a condition of possibility for world-disclosing, which is the main focus within the phenomenology of medicine, but also the view on the body as an affective givenness. I experience my body as an array of sensations, emotions and moods, such as pain, itching, tingling, anxiety, fear, nausea, disgust, euphoria and others. Secondly, the body's object-side has not been completely overlooked within the phenomenology of medicine either. Referring to both Husserl's ideas about the experience of one's body as a material thing (Körper) and Jean-Paul Sartre's ideas about the experience of the body in the mode of being for another (pour autrui), phenomenologists of medicine have focused

\footnotetext{
${ }^{1}$ Illness in the phenomenology of medicine and also in this paper refers to serious, chronic and life-changing ill health, as opposed to minor and transitory ailments (Carel, 2016, p. 2; Fisher, 2014, p. 42).
}

${ }^{2}$ A comprehensive view on the phenomenology of medicine is given by Fredrik Svenaeus (2016). 
on the alienation of the body in illness and the role the gaze of the other plays in this process (Svenaeus, 2009; Toombs, 1992; Leder, 1990; Carel, 2016). Zaner (1981, p. 50), Leder (1990, p. 82) and Toombs (1992, pp. 58-60) have written about the experience of one's body as an alien thing, leading to descriptions of its otherness in illness. They have also addressed the role the (internalized) gaze of the other plays in the process of experiencing one's body in illness, introducing an intersubjective dimension in the analysis of the experience of illness (Leder, 1990, p. 98; Toombs, 1992, p. 59). Recently, for example, this line of thought was further elaborated by feminist phenomenologist Linda Fisher (2014), and Jenny Slatman (2014b), who maintains that the experience of one's body is socially embedded (p. 556).

These and other descriptions of the embodied experience of illness which can be found in the literature of the phenomenology of medicine are based upon different dimensions of embodiment. In this paper I propose systematically laying out and describing multiple dimensions of the embodied experience of illness, which until recently has been the main focus within the phenomenology of medicine. In order to do this, I will return to the analysis of the nature of embodiment in Husserl's phenomenology. I will argue that on the basis of Husserl's phenomenology of the body one can distinguish four ways of experiencing one's body, or four dimensions of embodiment. I will distinguish between experience of one's body as 1) a bearer of sensations (the affective dimension of embodiment); 2) a seat of free movement, characterized by the faculty of "I can" (the functional dimension of embodiment); 3) a material thing in a causal relationship with the material world (the material dimension of embodiment); 4) a material thing embedded in a social context (the social dimension of embodiment). The proposed classification of the dimensions of embodiment serves two purposes: firstly, it provides a framework for the classification of the existing interpretations of the experience of illness; secondly, it opens up a way for a comprehensive analysis of the experience of illness which includes both individual and social aspects of embodiment as well as their mutual intertwining. ${ }^{3}$

I will start the paper with an overview of the main ideas concerning embodiment found in Husserl's phenomenology. In doing so, my aim is not to provide an in-depth analysis of Husserl's phenomenology of body, but to demonstrate that Husserl's ideas about the body allow one to account for the multiple dimensions of embodiment, including the experience of one's body as a subject and the experience of one's body as an object, both of which are useful in developing a comprehensive analysis of the experience of illness. I will then describe each of the four dimensions of embodiment, focusing on the way they have been used and elaborated within the phenomenology of medicine in illuminating various aspects of the experience of illness. While all four dimensions of embodiment have been addressed within the phenomenology of medicine and have contributed to the

\footnotetext{
${ }^{3}$ It should be noted that Slatman (2014b) has already made a classification of the dimensions of embodiment within the phenomenology of medicine. While I think that her work is especially important in indicating the need for a classification of embodiment and providing a distinction between the experience of one's body as a subject and as an object, it still needs adjustment to make further distinctions within the body's subject side and its object side.
} 
development of the phenomenology of illness, they have not (at least to my knowledge) been considered as a part of one theoretical framework which unites them all and considers their mutual relationship.

\section{Husserl and the Fourfold Perspective on One's Body}

Although Husserl's phenomenology of body is not the main source of influence for the phenomenology of medicine, ${ }^{4}$ it would be difficult to find a phenomenological account of a patient's lived experience without any reference to the distinction made by Husserl between Leib and Körper-between the living or lived body and the physical or objective body (Leder 1990, p. 5). As Aho \& Aho (2009) describe it, "Körper is a reference to the corporeal body, what we are as physiological, neurological, and skeletal beings. [...] In contrast, Leib concerns how we experience this physical matter in our everyday lives" (p. 1). It has been suggested that modern medical practices for the most part have relied on the paradigm of the physical body, given from the third-person perspective, without paying attention to how this body is lived or experienced from a first-person perspective (Leder, 1992; Macrum, 2004). This has led to biological interpretations of the patient's body which fall under the domain of empirical sciences, ignoring the meaning a patient attributes to the experience of her body. In order to rectify this omission, phenomenologists of medicine have tried to free Leib from Körper (Leder, 1990, p. 6), which means that they have tried to focus on the body as it is experienced by the patient from a firstperson perspective, prior to its theorization by science.

In what follows, in order to show that they illuminate complex dimensions of embodiment I will consider Husserl's ideas about Leib and Körper that were developed in his works Ideas II and Cartesian Meditations. I will argue that Husserl's analysis of the body does not juxtapose the physical body accessible from the third-person perspective and the lived body accessible from the first-person perspective; instead it presents different ways of experiencing one's body. In doing so, I agree with Leder's statement that it is common in the phenomenological literature to overemphasize or even ontologize the distinction between Leib and Körper. According to Leder (1990), and, as I will show, according to Husserl, the lived body and the physical body are not two different bodies: "Körper is itself an aspect of Leib, one manner in which the lived body shows itself' (p. 6). Based on this, I will demonstrate that Husserl's phenomenology of body provides a source for distinguishing four different ways of experiencing one's body, all of which have relevance for a comprehensive phenomenological account of the experience of illness.

When speaking about Husserl's ideas about the body, one usually refers to paragraphs in the second book of Ideas (2000/1952) in which he talks about the intentional constitution of the body. His well-known example in paragraph 36 about touching one's left hand with

\footnotetext{
${ }^{4}$ Svenaeus (2017) discerns two directions within contemporary proposals for a phenomenological interpretation of illness: one proceeds mainly from the philosophy of Merleau-Ponty (Leder, Toombs, Carel), the other from Heidegger (Gadamer, Aho, Svenaeus).
} 
one's right hand illustrates the double experience of one's body. Firstly, in touching my left hand with my right hand, I have "touch-appearances" of my left hand, meaning that I "perceive and have appearances of a soft, smooth hand, with such a form" (p. 152). These representational sensations of touch which belong to my right hand are objectified as features of the "left hand," which now appears to me as a thing. In other words, I experience my left hand as a physical thing with certain extension and properties. This is what Husserl calls experience of the object-body, or Körper. Secondly, when touching my left hand, according to Husserl, I find in it a "series of touch-sensations, which are 'localized' in it, though these are not constitutive of properties (such as roughness or smoothness of the hand, of this physical thing)" (p. 152). The left hand is not only felt, but also feels - it is also experienced as the location of sensations. Husserl writes:

If I speak of the physical thing, "left hand", then I am abstracting from these sensations [...] If I do include them, then it is not that the physical thing is now richer, but instead it becomes Body (Leib), it senses. (p. 152)

Among these sensations Husserl mentions sensations of touch, warmth, coldness, the pressure and pull of one's clothes, kinesthetic sensations, weight-sensations and the sensations of pleasure and pain (pp. 153, 158, 160). The presence of these localized sensations is what distinguishes a merely material thing from a lived body. One of the most important characteristics of the lived body is the fact it is inseparable from the ego. According to Husserl, I am the subject of the lived body (p. 157). In feeling hot or cold, pain or pleasure, I feel myself feeling. Thus the lived body expresses the experiential unity between the self (the ego) and the body. This does not apply to the experience of one's body as a merely material thing.

Husserl concludes that the lived body is originally constituted in a double way: as a physical thing or matter and as a bearer of localized sensations (p. 153). In other words, we experience our bodies as both feeling subjects and felt objects. According to Slatman and Yaron (2014), “One's own body can thus appear in two different modes: either as a thing or intentional object or as a localized lived-through experience of oneself" (p. 230). While Husserl has more to add to the constitution of the body as a material thing, in the context of this paper it is important to note that the perspective of the body as a material thing is not reserved solely for someone other than me (although this is the only perspective accessible for others) but is an integral part of experiencing one's own body. ${ }^{6}$ As the example of touching hands illustrates, my body appears to me both as a touching subject and a touched object. While most of the time these two perspectives of one's body coexist, it is possible, with the help of abstraction, to experience one's lived body just as a material

\footnotetext{
${ }^{5}$ Translators of Ideas II (2000) (André Schuwer and Richard Rojcewicz) propose translating Körper as body and Leib as Body (p. xiv). Apart from direct quotations, when rendering these terms in English in this paper I will be referring to the established convention within the field of phenomenology of medicine of translating Körper as body or object body and Leib as lived body.

${ }^{6}$ This was one of the central arguments of Jenny Slatman in her works on embodiment (2014a, 2014b; Slatman \& Yaron, 2014).
} 
thing. When I am abstracting from sensations localized "on" and "in" my lived body, it manifests to me as a material thing integrated into the causal nexus of material nature (Husserl, 2000, pp. 167-168). This can happen in both mundane experiences, such as "having one's arm go to sleep and experiencing it as a heavy, lifeless 'thing,," and in certain "limit situations" such as illness (Toombs, 1992, p. 59).

Based on what has been written so far, one can see that Husserl provided a twofold perspective on the experience of one's body; namely, it is experienced as a bearer of localized sensations and as a material thing. The latter expresses the material dimension of embodiment, while the former expresses the affective dimension of embodiment. There is, however, an important additional dimension of embodiment elaborated by Husserl. According to him (2000), the lived body is also experienced as seat of free movement, characterized by the faculty of "I can" (p. 159). Together with being the center of orientation, it serves as "means for all my perception" (pp. 166-167). Next to appearing as a bearer of sensations, the lived body "appears to us also as a freely moving organ (or system of organs) by means of which the subject experiences the external world" (p. 168) and constitutes it (including spatial objects as well as values) (p. 160). I can experience the external world, including my own material body, because "I 'can' perceive one hand 'by means of' the other, an eye by means of a hand, and so forth - a procedure in which the functioning organ must become an Object and the Object a functioning organ" (Husserl, 1982, p. 97). In Cartesian Meditations Husserl writes (1982/1950):

Among the bodies (Körpern) belonging to this "Nature" and included in my peculiar ownness, I then find my animate organism (Leib) as uniquely singled out [...] the only object "in" which I "rule and govern" (schalte und walte) immediately, governing particularly in each of its "organs". Touching kinesthetically, I perceive "with" my hands; seeing kinesthetically, I perceive also "with" my eyes; and so forth; moreover I can perceive thus at any time. Meanwhile the kinesthesias pertaining to the organs flow in the mode "I am doing", and are subject to my "I can" [...] (p. 97)

The "I can" expressed through the kinesthetic processes of the lived body illuminates the integral unity between the Ego or the subject and the body. The lived, sensing body is experienced as the seat of embodied agency and, because of that, as the source of the constitution of the object-world, "a world of spatial-corporeal things (the Body as thing included)" (Husserl, 2000, p. 159). I will call this "the functional dimension of embodiment."

In concluding his remarks on the constitution of the lived body in Ideas II, Husserl (2000) distinguishes three ways of experiencing one's body: 1) as a bearer of sensations; 2) as a seat of free movement, characterized by the faculty of "I can"; 3) as a material thing in a causal relationship with the material world (pp. 168-169). He notes that the first two ways of experiencing one's body are given from "within," while the third one is given from "outside" (p. 168). In other words, we can experience our body in the "inner" attitude as a subject and in the "outer" attitude as an object. It should be noted, however, that according to Husserl himself (2000), the experience of one's body from "without" is co-present with 
the experience of one's body from "within" (p. 169), which means that the experience of one's body as a material thing is also strictly speaking given in the "inner" attitude.

One can add another dimension of embodiment elaborated by Husserl that is related to the experience of one's body from "without." While in Ideas II Husserl (2000) provided a description of the constitution of the body for the solipsistic subject (p. 169), in Cartesian Meditations (1982) he takes into account the role the Other plays in this constitution. According to Husserl (1982), my lived body is the only body that is constituted originally as a lived body - a sensing and functioning body - while other bodies, which we also experience as lived bodies, derive this sense "by an apperceptive transfer from my animate organism (Leib)" (p. 111). Without going into details, Husserl argues that based on the similarity between my body and other bodies, we apprehend other bodies as animate or lived bodies by using an "analogizing" apprehension of that body as another animate organism (Leib)" (p. 112). Husserl describes this apprehension with reference to a specific kind of passive synthesis which he calls an original "pairing association" of the ego and the alter ego (p. 112). Due to this association, we find in our experience a "mutual transfer of sense, that is to say, an apperception of each according to the sense of the other" (p. 113). It is important to note that this transfer of meaning that occurs through the process of pairing is reciprocal (p. 120). Dan Zahavi (2012) explains: "In coming to understand the other, I draw on what I know from my own case, but through my encounter with the other, my own self-experience is also modified" (p. 236). According to Husserl (1982), in the community of persons (Menschengemeinschaft) there is an implicit "mutual being for one another" (p. 129). With this analysis he introduces another important dimension of embodiment; namely, the experience of one's body as it is perceived (seen, smelled, heard, etc.) by others, as was later elaborated by Jean-Paul Sartre (2001/1943).

Although Husserl himself did not develop this dimension of embodiment in detail, two important things should be mentioned: firstly, in talking about the experience of one's body as it is perceived by others, one talks about the experience of one's body from "the outside" and thus about the experience of the physical body (Körper). Secondly, because we are participating in a common world of social meanings and norms, the experience of my physical body as it is perceived by others is mediated by the wider social world, influencing the way I experience my body. Linda Fisher (2014) writes that "insofar as the intersubjective codetermining process unfolds and is embedded in the wider social world, it [...] involves a complex sociopolitical context" (p. 39). I will call this the "social dimension of embodiment."

It can be concluded that Husserl's phenomenology of the body entails a detailed classification of the various dimensions of embodiment, including experience of one's body as subject and experience of one's body as object. It shows that the view of the body as a material and social object is not reserved solely for someone other than me but is an integral part of experiencing one's body. ${ }^{7}$ In addition, it distinguishes between two ways of

\footnotetext{
${ }^{7}$ Rodemeyer (2014) also uses the division between the physical and the intersubjective body, based on her analysis of Husserl's notion of the body (Körper) (p. 197).
} 
experiencing one's body as a subject: as a bearer of sensations and as a seat of free movement. Overall, four dimensions of embodiment were distinguished. Due to the fact that these are not four different bodies, but four ways in which the lived body shows itself, it is important to note that they are not mutually exclusive. One experiences one's body as both a feeling and acting subject and as a felt and observed object. For this reason, the four dimensions of embodiment are intertwined with each other. In describing the role of each dimension of embodiment in the experience of illness, I will also try to sketch out their relation to other dimensions of embodiment, thus opening up a way for a richer interpretation of the experience of illness.

In what follows I will elaborate on four dimensions of embodiment in the context of the lived experience of illness as it has been described in the phenomenology of medicine. I will start with a description of the two dimensions of embodiment located on the body's subject-side and then proceed to a description of the remaining two dimensions of embodiment located on the body's object-side. Focusing on the body's subject-side, I will start with a description of the functional dimension of embodiment because it is the most influential in developing phenomenological interpretations of illness; I will then proceed to a description of the affective dimension of embodiment. Focusing on the body's object-side, I will describe the material and social dimensions of embodiment together. This is motivated by the fact that both of them have a common characteristic that is important in describing the experience of illness; namely, both of them entail the process of alienation of the body from the self.

\section{The Functional Dimension of Embodiment in the Experience of Illness}

The most widely described dimension of embodiment in the context of the phenomenological approach to the experience of illness is the functional dimension of embodiment. Although it was Husserl who introduced this dimension of embodiment within phenomenology, it was further developed by Maurice Merleau-Ponty (2014/1945) in his work Phenomenology of Perception. Without going into detailed analysis of Merleau-Ponty's phenomenology of the body, it is necessary to note that with the concept of the lived body (corps proper / corps vécu) Merleau-Ponty further develops Husserl's insights into the body as an embodied consciousness of "I can" which is responsible for the appearance of the world (2014, pp. 139, 147), thus emphasizing the fundamental unity between the body and the world. His point is that one endows one's world with meaning by bodily perception and movement (seeing, hearing, changing one's location, grasping, etc.). Slatman (2014b) writes:

According to him [Merleau-Ponty] the "I can" expresses the body as subject, as germ of activity and agency. The world does not appear to us because we think, but because we perceptually orientate ourselves in the world. (p. 553)

Merleau-Ponty describes this bodily orientation using the concept of "motor intentionality" (2014, p. 113), which expresses the fact that we are directed towards projects in the world through the intermediary of our body. The lived body can thus be described as the 
possibility of action in the world - the possibility of walking, talking, writing a paper, etc. Merleau-Ponty (2014) writes: "The body is the vehicle of being in the world and, for a living being, having a body means being united with a definite milieu, merging with certain projects, and being perpetually engaged therein" (p. 84). Usually we experience not the lived body itself (it recedes to the pre-reflective background), but things towards which we are intentionally directed. For example, instead of focusing on the way I am walking, I am focusing on the possibilities in the world towards which I am directed, such as, for example, crossing the street. This is why it has been said that most of the time we experience our body as transparent, absent or taken for granted (Leder, 1990).

Phenomenologists of medicine interested in describing the experience of illness have for the most part referred to the concept of the lived body expressed as the possibility of actions in the world, which illustrates the crucial importance the body has for freely engaging with one's environment and realizing one's projects. This is what I have called the functional dimension of embodiment. In illness this possibility of action becomes disrupted. Toombs (1992), for example, has described the experience of being ill as a disruption of the lived body (p. 62). According to her, it means that illness "represents dis-ability, the 'inability to' engage the world in habitual ways" (p. 62). Leder (1990) shares this view by stating that illness "is typified by complex patterns of dysfunction" (p. 81). In illness

one is actively dis-abled. Abilities that were previously in one's command and rightfully belong to the habitual body have been lost. This could be termed the phenomenon of the "I no longer can”. When sick, I no longer can engage the world as once I could. (Leder, 1990, p. 81)

Carel (2016) emphasizes the same point in characterizing the experience of illness as a breakdown of bodily certainty, or a breakdown of "the subtle feeling of 'I can' that pervades our actions" (p. 90). According to her, in illness one experiences bodily doubt and the "disruption of one's most fundamental sense of being in the world" (p. 92). ${ }^{8}$

The reference to the disruption of the functional dimension of embodiment in illness allows one to illuminate the fundamental dimension of the illness experience; namely, the fact that illness affects not only one's biological body, but also one's embodied being in the world in general, altering the experience of space, time, identity and relations to others. Toombs (1988) writes:

Illness is experienced by the patient not so much as a specific breakdown in the mechanical functioning of the biological body, but more fundamentally as a disintegration of his "world". [...] As such, it represents a chaotic disturbance in the various and varying interactions between embodied consciousness and world, and strikes at the very heart of the "I am" (p. 207).

In giving an in-depth account of her own experience of living with multiple sclerosis, an incurable, progressively disabling disease of the central nervous system, Toombs (2011)

\footnotetext{
${ }^{8}$ It should be noted here that when describing illness as the experience of "I no longer can," the aforementioned phenomenologists have in mind serious diseases that are progressively or abruptly disabling, especially focusing on the transition from health to illness. They are aware that this description is not entirely adequate in describing congenital disabilities.
} 
shows that she experiences her disease as a series of impossibilities - the impossibility of taking a walk around the block or climbing the stairs to reach the second floor-as well as the disruption of the experience of space and time (pp. 247, 254, 258). Making the same point, Leder (1992) writes: "When the body falls sick, we are left not simply with a broken machine, but with a world transformed; a disease undermines our sense of self and autonomy, our relations with others, our habitual experience of space and time" (p. 4). Illness is experienced not only as a disruption of one's biological body, but also as a disruption of the sense of the self, the experience of space, time and the relationship we have with other people. Consequently, the aim of both physicians and the healthcare system

should be not only to cure the patient's diseased part — if possible — but to help the patient resolve the disruption in the life-world and the anxiety associated with suffering from an illness. This can only be achieved by taking into account the meaning the patient attaches to illness and suffering. (Marcum, 2004, p. 317) ${ }^{9}$

\section{The Affective Dimension of Embodiment in the Experience of Illness}

The lived body is experienced not only as the possibility of action in the world, but also as a bearer of sensations. When we are ill, it is not just a matter of experiencing the disruption of one's engagements with the world - it is also an experience of a variety of novel sensations. As Leder (1990) writes: "The body when ill is a concert master not only of pain, but of warmth and cold, bloating, pressures, fatigues, nausea, tinglings, itches" (p. 82). Although this affective dimension of embodiment was introduced by Husserl, it has been further developed in contemporary French phenomenology, especially in the works of Michel Henry and Jean-Luc Marion. Without going into detailed analysis of the works of these French thinkers, it is important to note that instead of being interested in the relationship between the lived body and the world, both thinkers focused on the relationship of the lived body with itself. Henry (2002) criticized the common direction within the phenomenology of body, which, according to him, focuses solely on the relationship between the feeling body and what it feels (objects in the world and one's own body as an object) (p. 119). He writes: "What is overlooked in the present case is that the relationship of the feeling body [...] is not a relationship to what it feels or knows, but rather the relationship of this knowing, feeling body to itself' (p. 119). ${ }^{10}$ Following Henry's ideas, Marion (2002b) maintains that the feeling body relates to itself in affecting itself. It "is susceptible to radical affection in itself (self-affection)" and "originally it always autoaffects itself first in and by itself" (p. 231). As such, the feeling body appears as an "immanent succession of affections" without any external or preexisting affect (pp. 231-232).

\footnotetext{
${ }^{9}$ This is especially important in the rehabilitation process. According to Bullington (2009), a successful rehabilitation means "that the lived body has been restored to a harmonious field where the person can once again move freely on the mind-body continuum" (p. 108).

${ }^{10}$ The work is cited using Michael Tweed's translation (Henry, 2008).
} 
When we are affected with various feelings, they are given in our experience without reference to anything outside of them, namely, without any representative or intentional gap (Marion, 2002a, p. 91). For this reason, the feeling body appears as a nonintentional givenness of affections, ${ }^{11}$ namely, as a givenness which exceeds the intentional activity of the subject. As such, it is conceptually inexpressible and uncommunicable.

In addition to being inexpressible, another important characteristic of the feeling body is the fact that it is inseparable from the self. The experience of the feeling body or the flesh ${ }^{12}$ is always an immediate experience of oneself. Marion (2002a) maintains that I gain the sense of myself in feeling myself (p. 91) and that "I am [...] what affects me - my flesh" (2002b, p. 316). Moreover, the experience of flesh is unsubstitutable, for "nobody can enjoy or suffer for me" (2002b, p. 232), meaning that I can never actually be in doubt that the suffering or joy is mine. The affective dimension of embodiment thus illuminates both the fact that the embodied experience in question is always mine (unsubstitutable) and that, through this experience, I gain the sense of myself as the one who is affected. If applied to the experience of illness, this makes it possible to understand why sometimes unpleasant sensations, such as pain, may be welcomed by the sick person. In describing the experience of the psychiatric disorder anorexia nervosa, Svenaeus (2013) illustrates the role that pain plays in increasing self-awareness. In no longer feeling present in her body, the anorexic person may turn to self-mutilation (cutting herself) in order to increase the self-awareness through the pain (p. 88).

Within the phenomenology of medicine the affective dimension of embodiment has been primarily addressed in its relation to the functional and material dimensions of embodiment. This was done in detail by Leder (1990) in introducing and discussing the concept of bodily dys-appearance (pp. 83-99). It signifies the fact that in pain and illness the body appears as an obstacle and a limitation (something "bad" and "ill"), disappearing as a taken for granted condition of possibility for action (Leder, 1990, p. 84). ${ }^{13}$ His point is that the affective dimension of embodiment in illness (feelings of pain, nausea, anxiety etc.) may bring about both bodily objectification (the material dimension of embodiment) and bodily dysfunction (the functional dimension of embodiment). A strong pain in my stomach

\footnotetext{
${ }^{11}$ It is important to note that the givenness of affections is not restricted to the givenness of sensations (such as pain, hot and cold, itching etc.); it also includes feelings of well-being, disgust, discomfort etc. (Rodemeyer, 2014, p. 190). Husserl (2000) described them all using the term sensings (Empfindnisse) (p. 153). Marion uses both the term affections and the term feelings, without making any distinction between the two (2002b, pp. 231232; 2002a, pp. 85-91). Based on the examples he has given, affections include a cluster of experiences, such as pain, suffering, fatigue, nausea, anxiety, irritability, helplessness, sadness, itchiness, etc.

${ }^{12}$ Marion (2002a, 2002b) uses the term la chair (translated in English as flesh), instead of the terms corps vécu or corps propre (translated in English as lived body), in order to emphasize the nonintentional character of the experienced body. It should be noted that the term la chair had already been used before Marion by Maurice Merleau-Ponty in his later works, and by Michel Henry.

${ }^{13}$ Zeiler (2010) has suggested that the body can appear to the subject as a thematic focus, without appearing as something negative. She has described bodily modes of being in which the body appears to the subject as something good, easy or well, such as physical exercise, sexual pleasure and in some cases wanted pregnancies.
} 
forces me to focus on this part of the body, closing down the possibilities of walking to the park, talking to the friend etc. Moreover, the affective and functional dimensions of embodiment are mutually reinforcing. The givenness of affections in illness, such as pain, tingling, fatigue etc. may reinforce the curtailment of functions in illness (because of the pain, for example, I am no longer able to stand up), and, vice versa, the curtailment of functions (the inability to stand up) may reinforce anxiety, fear and other emotions (the affective dimension of embodiment).

When focusing on the concept of mood which he found in Heidegger's philosophy, Svenaeus (2014) addressed the role of the affective dimension in illness and its connection to the functional dimension of embodiment. He is especially interested in the analysis of suffering moods such as anxiety, fear, sadness, boredom, helplessness, despair, shame, and self-hatred (p. 415), which are essential ingredients in a variety of illnesses, especially mental disorders. Moods, according to him, "determine the way the whole world appears to us" (p. 409), providing it with a meaning and coherence. His point is that the world appears to us based on the moods we have: "the world of the pain sufferer is totally different from the world of the happy enjoyer, in wholes as well as bits" (p. 410). Based on this, it is possible to say that illness is experienced not just as a givenness of bodily sensations, but also as a form of "being-in-the-world," involving the way a person acts in the world and relates to others and herself. This insight illuminates the connection between the affective and functional dimensions of embodiment - the complex of feelings present in illness "affects the person's way of living in the world of human goals and projects" (p. 413). The sensation of pain or the emotion of shame, for example, do not amount only to the experience of the body as an alien thing (the material dimension of embodiment): being transformed into moods, they influence the way one engages with the world, disrupting one's possibilities of action and changing the way one approaches one's past and future (the functional dimension of embodiment).

The intertwining of the affective dimension of embodiment with the functional dimension of embodiment in illness also manifests itself in the linguistic dis-ability experienced by a sick person. Because the givenness of affections in illness is conceptually inexpressible, a sick person is never able to adequately express and communicate what is happening to her (What is it exactly that I am feeling? How can I explain this feeling to others? Why has this happened to me?). The fact that it is difficult or impossible to adequately express one's feelings in illness has implications for the clinical encounter. Usually in describing their feelings to a physician, patients are forced to use already established forms of expression, which are approximate (pain level is 7) and metaphorical (I feel sharp pain). Without being sensitive to this experiential aspect of illness, physicians may interpret the inability to express oneself at all or only indecisively as either a sign of the superficiality of the problem or as a sign of pretense. Although this inexpressibility of affections is not something that can be avoided, if taken into account in doctor-patient communication, it can help to illuminate the origins of misunderstandings on both parts. 


\section{The Material and Social Dimensions of Embodiment in the Experience of Illness}

We experience our bodies not only as subjects - the taken for granted conditions of our actions and the givenness of affectivity - but also as objects. As shown in the first part of the paper, this experience of one's body as an object includes the experience of the body as a material object (the material dimension of embodiment) as well as the experience of the body as a social reality that is subjected to intersubjective appropriation (the social dimension of embodiment). These two dimensions of embodiment are intertwined very closely: the material dimension of embodiment is a necessary condition for the social dimension of embodiment; my body is subjected to different interpretations precisely because it is a physical thing accessible to others. Moreover, the social dimension of embodiment influences the material dimension of embodiment: one's material body abstracted from sensations may become subjected to the interpersonal sociocultural (scientific, aesthetic, moral, political etc.) horizon of meaning. This in turn leads to the experience of one's body as a biological organism, as a beautiful body, as an abnormal body etc.

\subsection{The Material Dimension of Embodiment}

The material dimension of embodiment comes into play in describing the disruption of the lived body in illness: when one no longer focuses on projects in the world, but instead is forced to focus on the body itself, it appears as a material object. Thus the disruption of the functional dimension of embodiment in illness (the experience of "I cannot") is intertwined with the experience of one's body as a material object. As already mentioned, Leder describes it as bodily dys-appearance, expressing the fact that in some situations, including illness, the body appears as an explicit material object, at the same time disappearing as a transparent condition for the possibility of actions in the world. It should also be noted that in experiencing one's body as an object, one no longer experiences the unity between the body and the self that is present in experiencing one's body as an active and feeling subject. This is why the experience of one's body as a material object in illness has been characterized as the experience of alienation between the self and the body.

The experience of one's body as an object in illness (and the corresponding experience of alienation of the body from the self) has two sources: the gaze of the Other and one's body itself (Leder, pp. 92-99; Zaner, 1981, pp. 47-66; Svenaeus, 2009, pp. 59-60). I may be forced to focus on my body as an object either because I perceive it (or part of it) as somehow deviating from accepted standards and norms, or because the body itself (for example, sensations of pain, unwanted physiological reactions or physical damage) demands my attention. The latter cause of bodily objectification, i.e. the body itself, includes both affective and motor disturbances (Leder, 1990, p. 85). According to Leder (1990), I may become aware of my body as an object either because of affective disturbances (in feeling anxious and starting to sweat, I am forced to focus on my body) or because of the dysfunctions in the motor sphere (in stumbling on the street, I become aware of my legs) (p. 85). This illustrates the close connection between the material dimension of embodiment and the affective 
and functional dimensions of embodiment. The experience of discomfort in illness (especially in the case of the givenness of strong and/or unexpected sensations) may lead to the awareness of one's body as an object (the material dimension of the embodiment). ${ }^{14}$ I may step on a nail and the sharp pain which overwhelms me (the affective dimension of embodiment) may force me to focus on my foot (the material dimension of embodiment). Vice versa, the awareness of one's body as an object (either based on the gaze of the Other, dysfunction in the motor sphere, or affective disturbances) may trigger a variety of affections such as fear, anxiety, nausea, etc. The awareness of the body as disgusting or damaged may lead to feelings of helplessness, fear, anxiety and suffering.

The same mutuality applies to the relationship between the material and functional dimensions of embodiment. The sharp curtailment of functions in illness correlates with the awareness of my body as an object. For example, if I cannot move my hands anymore, I am forced to reflect back upon the body itself (Leder, 1990, p. 82). It also works the other way around: the objectification of the body leads to the disruption of the possibilities of action in the world. If I am forced to focus on my body (either because of the gaze of the Other, dysfunction in the motor sphere, or affective disturbances), I may no longer be able to engage with the world in a habitual way. The awareness of the body as disgusting or damaged may trigger or at least intensify my inability to focus on the lecture and engage in a conversation.

Overall, it can be said that when we fall ill, the body itself (through the affective and functional dimensions of embodiment) demands our attention, forcing us to become aware of it as an object (the material dimension of embodiment) which takes up space and can be subjected to a different kinds of manipulation. Zaner (1981) writes:

My body, like the world in which I live, has its own nature, functions, structures, and biological conditions. [...] Under certain conditions, it can fail me (more or less), not be capable of fulfilling my wants and desires, or even thoughts, forcing me to turn away from what I may want to do and attend to my own body. (p. 52)

In illness my body appears as an alien presence, as something strange, unfamiliar and uncontrollable. ${ }^{15}$ As such it expresses the material dimension of embodiment as well as its close connection to the affective and functional dimensions of embodiment. Before proceeding to the description of the social dimension of embodiment, it should be noted that the intertwining between the material and affective dimensions of embodiment illuminates another important aspect of the illness experience: the simultaneous experience of mineness and alienation in illness, often mentioned within the phenomenological investigations

\footnotetext{
${ }^{14}$ Although the givenness of sensations is usually associated with the awareness of one's body or part of the body, this awareness does not necessarily coincide with the thematization of one's body as an object or with the objectification of one's body. It is possible to be aware of one's affective body without objectifying it. This point is illustrated by Martiny (2015) when distinguishing different levels of experiencing disability.

${ }^{15}$ Zaner (1981) uses the term uncanny (Unheimliche) in order to illuminate the sense of the body's otherness (pp. 48-66).
} 
of the illness experience (Leder, 1990, p. 85; Svenaeus, 2011, p. 337). In illness I may experience my body as an alien object which acts against me (leading to the alienation between the self and the body), but, at the same time, in being affected by pain, anxiety, or other feelings, I also experience the body as being mine.

\subsection{The Social Dimension of Embodiment}

In what follows I will focus on the second source of bodily objectification, namely, the gaze of the Other, which was explicitly addressed by Jean-Paul Sartre. According to Sartre (2001/1943), the gaze of the Other is the most important source of bodily objectification and alienation. ${ }^{16} \mathrm{He}$ writes: "With the appearance of the Other's look I experience the revelation of my being-as-object" (p. 351). This amounts to existing for oneself (pour soi) in the mode of being for another (pour autrui). This presupposes that, to some degree at least, I adopt the perspective that others have on my body, namely, the perspective of my body as an object. Leder (1990) writes: "I put myself in their place, assume their perspective, just as they do mine" (p. 95). This mutual incorporation was already described by Husserl, emphasizing the intersubjective appropriation of the body and opening up a way for description of the social dimension of embodiment. According to Slatman (2014b), "In the field of health and medicine this is highly relevant, since most illnesses and disabilities go together with some sort of appearance-related issues, or with changes in one's perceptible manifestation in the world" (p. 550).

Leder (1990) described the objectification of one's body which is brought about by the incorporated gaze of the Other as social dys-appearance (p. 97). It is important to note that social dys-appearance is mediated by the wider social world, which includes ethical context (I may become aware of my sick body as unacceptable, based on moral norms), aesthetic context (I may become aware of my sick body as unattractive, based on standards of beauty and attractiveness) as well as scientific context (I may become aware of my sick body as a collection of damaged organs, based on the scientific discourse of meaning) among others (Leder, 1990, pp. 97-98). Based on the importance of the gaze of the Other on the experience of one's body, it has been suggested that phenomenologists of medicine should acknowledge the role the social context plays in the experience of illness (Fisher, 2014; Slatman, 2014b). Slatman and Yaron (2014) showed that the experience of one's disfigured body in illness is primarily the experience of one's body as an object for the Other's gaze - "an object that is labeled as strange, different, fascinating, or repulsive and receives a discursive, symbolic meaning in relation to valorized, opposing terms such as 'acceptable,' 'normal,' 'common,' or 'attractive'” (p. 231). They also emphasized the importance the social dimension of embodiment plays in the loss of one's abilities (the

\footnotetext{
${ }^{16}$ It should be noted that Sartre's account of bodily objectification, based on the gaze of the Other, has been criticized on many points, two of which should be mentioned here. On the one hand, it has been argued that the gaze of the Other does not necessarily lead to the objectification of one's body. On the other hand, it has been pointed out that the gaze of the Other is not the only source of bodily objectification (Leder, 1990, pp. 93-99; Svenaeus, 2009, p. 60).
} 
functional dimension of embodiment), suggesting that the experience of disability may not necessarily result from the damage to the functions of one's physical body, but can be traced back to society.

I will now sketch out the intertwining of the social, functional and affective dimensions of embodiment in the experience of illness. Experience of one's body as an inadequate object (the social dimension of embodiment) influences both one's ability to do things in the world (the functional dimension of embodiment) and one's feelings and emotions (the affective dimension of embodiment). In referring to a case of a disfiguring cancer, Slatman (2014b) illustrates how the experience of one's disfigured body can change one's agency. Based on interviews conducted within her research project, ${ }^{17}$ she describes how Janet (a fictional name for one of her respondents) experiences her body after undergoing a mastectomy and wearing an external breast prosthesis (pp. 554-555). Slatman argues that Janet's lived experiences of agency (possibilities of going out and seeing other people) are influenced by the way she experiences her body as it is accessible to others - in this case, not conforming to the prevailing norms of feminine embodiment. The fact that she cannot go out of the house without her prosthesis illustrates the close relationship of the functional and social dimensions of embodiment. Slatman (2014b) writes:

Her agency and subjectivity, i.e., her possibility to act within the world, to go out and see other people, is dependent of the usage of a prosthesis, and thus dependent on how others perceive her, and thus of an external view on her body, her body as object (p. 555).

This illustrates the fact that the experience of disability may be motivated not only by the physical, but also by the social body. A person may experience disability even if her bodily functions are not impaired. Also, it has been argued that even in the case of congenital disabilities, when there is actual damage to the physical body, the experience of disability is also constituted by the social context (Martiny, 2015). Since everyone experiences themselves and their abilities as their own normal point of departure, there is no experience of disability within the solitary ego. It is precisely because the embodied agency of "I can" is influenced by social norms and expectations that one develops an experience of being disabled.

The social dimension of embodiment is also intertwined with the affective dimension of embodiment. In many instances of being ill (especially in cases of visible disfigurements and disordered body style), the internalized perspective on one's body as an inadequate object leads to feelings of shame, anxiety, fear etc. (the affective dimension of embodiment). Toombs (2001) writes:

Feelings of shame inevitably accompany the changes in body that elicit negative responses from others. Every time I have had to adopt a new way of getting around the world, first a cane, then crutches, then walker, and finally a wheelchair, I have experienced feelings of shame. (p. 257)

\footnotetext{
${ }^{17}$ In this project, by means of multiple interviews, for a period of 8-10 months Slatman "followed" 19 women who underwent breast surgery (2014b, p. 554).
} 
These feelings (the affective dimension of embodiment) in their turn may lead to the disruption of one's embodied agency of "I can" (the functional dimension of embodiment). For example, a person who is ashamed of her body may be unable to visit a doctor or may not be able to tell her the truth about her condition. This inability may be reinforced by one's perceived responsibility for an illness (ethical horizon of meaning). One may avoid clinical settings because one is afraid of being judged or shamed by the doctor for one's health-related behavior. Dolezal (2015) writes:

In our cultural context which values autonomy, discipline and self-restraint, illnesses associated with alcoholism, addiction, sexual activity or overeating are strongly stigmatized, and afflicted individuals are made to feel ashamed of their supposed lack of self-control and weak will. (p. 572)

Moreover, feelings of shame in the clinical encounter may be reinforced by the actual gaze of the physician on one's exposed body (p. 573). ${ }^{18}$ Because feelings of shame and anxiety, which are reinforced by the view of one's body as being-for-the-Other, lead to the disruption of one's possibilities of action in the world, including the possibility to deal with one's problem, it has been suggested that patients' testimonies about their emotional states should be taken into account. In order to facilitate positive health outcomes, doctors should acknowledge the significance the experience of shame and other emotions has for the patient (Dolezal, 2015, pp. 574-575).

In addition to what has already been already written, the social dimension of embodiment in combination with the affective dimension of embodiment correlates with the material dimension of embodiment. Feelings of shame, which are reinforced by the view of one's body as being-for-the-Other (the social dimension of embodiment), involve "a whole slew of involuntary physiological reactions, which also bring awareness of the physical body" (Dolezal, 2015, p. 570). Feelings of shame intensify the awareness of one's body as a (trembling, blushing, sweating, etc.) material thing, which may lead to the disruption of one's possibilities of action in the world. Toombs (2001) writes:

In many types of neurological disorder shame manifests itself as an increase in the severity of symptoms. In the experience of the Other's "gaze" an already existing tremor invariably intensifies, spastic limbs become more rigid, difficulty in controlling movement is more pronounced. (p. 257)

This leads to both the awareness of one's body as a material thing, which is distinct from the self, and to the incapacity to engage with the world in a habitual way.

It can be concluded that the experience of one's body as an object accessible to the gaze of the Other (the social dimension of embodiment) leads to the experience of alienation

\footnotetext{
${ }^{18}$ However, to feel shame and other emotions it is not necessary that one is actually observed by another person, "more often than not the 'gaze' of the Other is concrete" (Toombs, 2001, p. 256). A person may directly experience responses of other people - their facial expressions, gestures, averted eyes, irritation, etc. (p. 56). This is especially important in the clinical encounter, when the gaze of the doctor may directly influence the patient's experience of her body.
} 
(the material dimension of embodiment), evokes affectivity (shame, anxiety, fear etc.) (the affective dimension of embodiment) and may hinder one's embodied agency of "I can" (the functional dimension of embodiment).

\section{Conclusion}

In this paper I have tried to systematically lay out and describe multiple dimensions of the embodied experience of illness, which until recently has been the main focus within the field of the phenomenology of medicine. In order to do so, I turned to analysis of the nature of embodiment in Husserl's phenomenology. I argued that based on Husserl's ideas about the body, four ways of experiencing one's body or the four dimensions of embodiment can be distinguished: 1) one's body as a bearer of sensations (the affective dimension of embodiment); 2) one's body as a seat of free movement, characterized by the faculty of "I can" (the functional dimension of embodiment); 3 ) one's body as a material thing in a causal relationship with the material world (the material dimension of embodiment); 4) one's body as a material thing embedded in a social context (the social dimension of embodiment). It was concluded that one experiences one's body both as a feeling and acting subject and as a felt and observed object, illuminating both the individual and social dimensions of embodiment. In addition, it was also emphasized that the four dimensions of embodiment are mutually intertwined.

The proposed classification of dimensions of embodiment was then applied to the experience of illness, focusing on the different ways these dimensions are addressed within the phenomenology of medicine. This was done, firstly, in order to provide a framework for the classification of the existing interpretations of the experience of illness and, secondly, in order to open up a way for a comprehensive analysis of the experience of illness which would include both individual and social aspects of embodiment as well as their mutual intertwining. It was demonstrated that illness is experienced as a disruption of the possibilities of action in the world (the functional dimension of embodiment), as a givenness of inexpressible sensations, emotions and moods (the affective dimension of embodiment), as an objectification of one's body as an alien and strange thing (the material dimension of embodiment), and as the objectification of one's body as a disgusting, abnormal or ugly thing, based on the gaze of the Other (the social dimension of embodiment). In addition to that, it was also demonstrated that all four dimensions of embodiment are closely intertwined in the experience of illness.

It should be noted that although the proposed classification of the four dimensions of embodiment gives valuable insights into the experience of illness, it is not exhaustive. One thing that was not considered in this paper was the productive dimension of the illness experience. While the experience of illness can definitely be described as the "inability to" do something, it can also open up possibilities of perception, action and self-understanding that enrich one's life. Thus, instead of being disabling, illness can also be enabling. This insight is especially important in considering the issues of identity formation 
of a person with illness and disability. In the absence (or transformation) of the dominant social norms regarding disability as something negative, a person with disability may not experience it as such. Instead, in providing unique possibilities of perception and selfunderstanding, the experience itself may open up a way for the transformation of one's identity from something negative to something positive. In order to gain a more complete insight into the experience of illness, the focus on the productive dimension of the illness experience and the related issues regarding the formation/transformation of the identity of a sick person require further elaboration.

The proposed classification of the four dimensions of embodiment within illness could also be further elaborated by considering the specific ways in which these dimensions of embodiment are intertwined within different types of illness such as mental and somatic disorders, acute and chronic illnesses, as well as acquired and congenital illnesses. This could lead to insights regarding similarities/differences in experiencing different types of illness as well as to insights about the essential dimensions of embodiment regarding the nature of illness as such. In addition to this, the proposed classification of the four dimensions of embodiment within illness could be further elaborated by considering the perspective of the medical professional of both the patient's body and her own.

\section{References}

Aho, J., \& Aho, K. (2009). Body matters: A phenomenology of sickness, disease, and illness. Lanham, MD: Lexington Books.

Aho, K. (2013). Depression and embodiment: Phenomenological reflections on motility, affectivity, and transcendence. Medicine, Health Care and Philosophy, 16(4), 751-759. https://doi.org/10.1007/s11019-013-9470-8

Bullington, J. (2009). Embodiment and chronic pain: Implications for rehabilitation practice. Health Care Analysis, 17(2), 100-109. https://doi.org/10.1007/s10728-008-0109-5

Carel, H. (2008). Illness: The cry of the flesh. London, UK: Routledge.

Carel, H. (2016). Phenomenology of illness. Oxford, UK: Oxford University Press.

Dolezal, L. (2015). The phenomenology of shame in the clinical encounter. Medicine, Health Care and Philosophy, 18(4), 567-576. https://doi.org/10.1007/s11019-015-9654-5

Fisher, L. (2014). The illness experience: A feminist phenomenological perspective. In: K. Zeiler \& L. F. Käll (Eds.), Feminist phenomenology and medicine (pp. 27-46). New York, NY: SUNY Press.

Henry, M. (2004). Le corps vivant. In M. Uhl (Ed.) Auto-donation: Entretiens et conférences (pp. 111-138). Paris, France: Editions Beauchesne.

Henry, M. (2008). The living body. (M. Tweeds, Trans.). Retreived 2018, September 20 from http://www.academia.edu/5595141/The_Living_Body_by_Michel_Henry 
Husserl, E. (1982). Cartesian meditations: An introduction to phenomenology. (D. Cairns, Trans.). The Hague, the Netherlands: Martinus Nijhoff Publishers. (Original work published 1950)

Husserl, E. (2000). Ideas pertaining to a pure phenomenology and to a phenomenological philosophy: Second book: Studies in the phenomenology of constitution. (A. Schuwer \& R. Rojcewicz, Transl.). Dordrecht, the Netherlands: Springer.

Leder, D. (1990). The absent body. Chicago, IL: University of Chicago Press.

Leder, D. (1992). Introduction. In D. Leder (Ed.), The body in medical thought and practice (pp. 1-16). Dordrecht, the Netherlands: Springer.

Leder, D. (2016). The distressed body: Rethinking illness, imprisonment, and healing. Chicago, IL: University of Chicago Press.

Marcum, J. A. (2004). Biomechanical and phenomenological models of the body, the meaning of illness and quality of care. Medicine, Health Care and Philosophy, 7(3), 311-320. https://doi.org/10.1007/s11019-004-9033-0

Marion, J.-L. (2002a). In excess: Studies of saturated phenomena. (R. Horner \& V. Berraud, Trans.). New York, NY: Fordham University Press. (Original work published 2001)

Marion, J.-L. (2002b). Being given: Towards phenomenology of givenness. (J. L. Kosky, Trans.). Stanford, CA: Stanford University Press. (Original work published 1997)

Martiny, K. M. (2015). How to develop a phenomenologist model of disability. Medicine, Health Care and Philosophy, 18(4), 553-565. https://doi.org/10.1007/s11019-015-9625-x

Merleau-Ponty, M. (2014). Phenomenology of perception. (D. A. Landes, Trans.). London, UK: Routledge. (Original work published 1945)

Rodemeyer, M. L. (2014). Feminism, Phenomenology, and Hormones. In K. Zeiler \& L. F. Käll (Eds.), Feminist phenomenology and medicine (pp. 183-199). New York, NY: SUNY Press.

Sartre, J.-P. (2001). Being and Nothingness. (H. E. Barnes, Trans.). London, UK: Routledge. (Original work published 1943)

Slatman, J. (2014a). Our strange body: Philosophical reflections on identity and medical interventions. Amsterdam, the Netherlands: Amsterdam University Press.

Slatman, J. (2014b). Multiple dimensions of embodiment in medical practices. Medicine, Health Care and Philosophy, 17(4), 549-557. https://doi.org/10.1007/s11019-014-9544-2

Slatman, J. \& Yaron G. (2014). Toward a phenomenology of disfigurement. In K. Zeiler \& L. F. Käll (Eds.), Feminist phenomenology and medicine (pp. 223-240). New York, NY: SUNY Press.

Svenaeus, F. (2000a). Das Unheimliche - towards a phenomenology of illness. Medicine, Health Care and Philosophy, 3(1), 3-16. https://doi.org/10.1023/A:1009943524301

Svenaeus, F. (2000b). The body uncanny - further steps towards a phenomenology of illness. Medicine, Health Care and Philosophy, 3(2), 125-137. https://doi.org/10.1023/A:1009920011164

Svenaeus, F. (2009). The phenomenology of falling ill: An explication, critique and improvement of Sartre's theory of embodiment and alienation. Human Studies, 32(1), 53-66.

https://doi.org/10.1007/s10746-009-9109-1 
Svenaeus, F. (2011). Illness as unhomelike being-in-the-world: Heidegger and the phenomenology of medicine. Medicine, Health Care and Philosophy, 14(3), 333-343.

https://doi.org/10.1007/s11019-010-9301-0

Svenaeus, F. (2016). Phenomenology and medicine. In J. A. Marcum (Ed.) The Bloomsbury companion to contemporary philosophy of medicine (pp. 205-226). London, UK: Bloomsbury Academic.

Svenaeus, F. (2017). A Defense of the Phenomenological Account of Health and Illness [article].

Retrieved September 20, 2018 from http://www.academia.edu/32533542/A_De-

fence_of_the_Phenomenological_Account_of_Health_and_Illness

Svenaeus, F. (2018). Phenomenological bioethics: Medical technologies, human suffering, and the meaning of being alive. London, UK: Routledge.

Toombs, K. S. (1987). The meaning of illness: A phenomenological approach to the patient-physician relationship. The Journal of Medicine and Philosophy, 12(3), 219-240. https://doi.org/10.1093/jmp/12.3.219

Toombs, K. S. (1992). The meaning of illness: A phenomenological account of the different perspectives of the physician and patient. Boston: Kluwer Academic Publishers.

Toombs, K. S. (2001). Reflections on bodily change: The lived experience of disability. In S. K. Toombs (Ed.), Handbook of phenomenology and medicine (pp. 247-261). Dordrecht, the Netherlands: Springer.

Zahavi, D. (2012). Empathy and mirroring: Husserl and Gallese. In R. Breeur \& U. Melle (Eds.), Life, subjectivity \& art: Essays in honor of Rudolf Bernet, Phaenomenologica 201 (pp. 217 254). Dordrecht, the Netherlands: Springer. https://doi.org/10.1007/978-94-007-2211-8

Zaner, R. (1981). The context of self: A phenomenological inquiry using medicine as a clue. Athens, OH: Ohio University Press.

Zeiler, K. (2010). A phenomenological analysis of bodily self-awareness in the experience of pain and pleasure: On dys-appearance and eu-appearance. Medicine, Health Care and Philosophy, 13(4), 333-342. https://doi.org/10.1007/s11019-010-9237-4

Zeiler, K., \& Käll, F. L. (Eds.). (2014). Feminist phenomenology and medicine. New York, NY: SUNY Press. 